\title{
O ensino religioso em diálogo com o curso de Ciências das Religiões da Universidade Federal da Paraíba
}

\author{
Doracy Rocha Lopes ${ }^{1}$ \\ Silvania Maria da Silva ${ }^{2}$ \\ Eunice Simões Lins Gomes ${ }^{3}$
}

\section{RESUMO}

Nosso objetivo consiste em analisar como se encontra o Ensino Religioso em dialogo com as Ciências das Religiões no município de João Pessoa - PB nos dias atuais. Partimos do pressuposto de que o Ensino Religioso assegura o respeito à diversidade cultural religiosa, enquanto as Ciências das Religiões visam compreender o fenômeno religioso em suas dimensões e formar o professor/a para ministrar nas escolas na perspectiva da diversidade cultural religiosa. A metodologia de investigação foi à pesquisa descritiva, bibliográfica e fontes documentais.

\section{PALAVRAS-CHAVE}

Ensino Religioso. Ciências das Religiões. Formação e Docência.
ABSTRACT
Our goal is an analysis of the dialogue between Religious Teaching and Sciences of the Religions in João Pessoa - Paraiba no wadays. We

\footnotetext{
${ }^{1}$ Doracy Rocha Lopes - Graduanda em Ciências das Religiões - UFPB.

${ }^{2}$ Silvania Maria da Silva - Graduanda em Ciências das Religiões - UFPB.

${ }^{3}$ Profa. Pós-doutora no Programa de Pós Graduação e no Departamento de Ciências das Religiões da UFPB.
} 
start from the assumption that Religious Teaching assures respect for cultural religious diversity, while the Sciences of the Religions seek to comprehend the religious phenomenon in its dimensions. Sciences of Religions also educate teachers for ministering in classroom from the perspective of religious diversity. The research methodology was descriptive research, bibliographic and documentary sources.

\section{KEYWORDS}

Religious Teaching. Sciences of the Religions. FormationandTeaching.

\section{Introdução}

Neste artigo propomo-nos a tentativa de descrever como o Ensino Religioso está sendo desenvolvido nas escolas da rede municipal de João Pessoa-PB, tendo por base o estudo etnográfico e a experiência por meio de um estágio supervisionado que teve por objetivo a observação participante na sala de aula e registro de dados efetuados no diário de campo.

Foi possível perceber em nossa pesquisa que o Ensino Religioso vem ocupando umlugar relevante, tendo em vista que deu grande passo com relação a um discurso menos proselitista, onde se seguia o modelo catequético e o modelo teológico, ocupando atualmente um discurso mais próximo da diversidade religiosa, onde o respeito às culturas e tradições religiosas se fazpresente na sala de aula.

Seguindo essa perspectiva, é possível perceber que o curso de Ciências das Religiões na Universidade Federal da Paraíba tem como proposta proporcionar uma educação de qualidade direcionada a diversidade religiosa, sem favorecer nenhuma instituição religiosa, disseminando o respeito e a curiosidade à cultura do outro.

Desse modo, ressaltamos que o ponto de partida foi o surgimento do curso de Especialização em Ciências das Religiões na Universidade Federal da Paraíba no ano de 2005, em parceria com o Centro de Educação da Universidade Federal da Paraíba (CE-UFPB), para professores que ministravam aula de Ensino Religioso nas escolas de rede estadual 
da Paraíba. Em 2006, a Secretaria Municipal de Educação e Cultura de João Pessoa (SEDEC-JP) implantou esse componente curricular para seus professores. Surgiu, então, a necessidade de criar um curso de licenciatura em Ciências das Religiões fazendo o uso em sua grade curricular do pluralismo religioso e do respeito à diversidade religiosa.

\section{O Ensino Religioso na Rede Municipal}

A Secretaria de Educação e Cultura do Município de João Pessoa (SEDEC-JP) tem como objetivo organizar, executar, manter, orientar, coordenar e controlar as atividades do poder público ligado à educação municipal. A rede de Ensino Municipal conta hoje com noventa e duas (92) escolas e trinta e nove (39) Centros de Referência de Educação Infantil - CREIS (antigas creches).

Foi possível perceber o grande avanço e abertura para a diversidade religiosa dentro das escolas municipais, foco de nossa análise, tendo em vista a procura de alguns professores da rede municipal de ensino de João Pessoa para uma formação especifica e não proselitista fornecida pela SEDEC e pelo CE-UFPB.

Considerando que o Ensino Religioso não é uma matéria obrigatória e, sim, optativa, a grande luta diante de autoridades maiores responsáveis por essa mudança tem sido intensa. A nova metodologia apresentada para a ministração de Ensino Religioso nas salas de aulas deverá acontecer um olhar atencioso frente a essa realidade.

Entretanto, é perceptível o investimento no Ensino Religioso na rede municipal de João Pessoa até mesmo pela postura realizada pelo secretário Municipal de Educação e Cultural, Luiz de Sousa Junior, segundo o Jornal da Paraíba de 26 de janeiro de 2013:

As Escolas da rede pública municipal de João Pessoa estão obrigadas, desde o dia 8 de janeiro, a oferecer o Ensino religioso na grade curricular do Ensino fundamental. Porém, os alunos não estão obrigados a fazer matrícula na disciplina. A regra passou a valer após o secretário Municipal de Educação e Cultura, Luiz de Sousa Junior, homologar a Resolução 026/12 instituída pelo Con- 
selho Municipal de Educação. A medida, prevista na Lei Federal de Diretrizes e Bases da Educação Nacional (LDB n. 9.394/96 com nova redação na Lei 9.475/97) e no artigo 11 do Anexo do Decreto $\mathrm{n}^{\mathrm{o}} 7.107 / 2010$, já vale para o ano letivo 2013. De acordo com Art. $2^{\circ}$ do documento, o componente curricular vai "subsidiar o estudante para compreensão do fenômeno religioso, presente nas diversas culturas e sistematizado por todas as tradições religiosas". No parágrafo único do mesmo artigo, diz que, nas Escolas públicas municipais, não será permitido qualquer tipo de preconceito ou manifestação em desacordo com o direito individual do estudante e de seus familiares, de declarar um credo religioso ou mesmo o de não exercer nenhum. Segundo a lei, no ato da matrícula, a instituição deverá informar ao estudante, ou aos pais, quando de menor idade, a oferta do Ensino religioso, bem como a faculdade de matricular-se no mesmo. O conteúdo pedagógico tem caráter inter-religioso, distinto da catequese, onde deverá pautar na contextualização do conhecimento, reconhecendo que o fenômeno religioso é um dado da cultura e da identidade de grupos sociais, que deve promover o sentido da tolerância e do convívio respeitoso com o diferente. O Ensino religioso deverá ser ofertado no horário normal das Escolas públicas municipais de Ensino fundamental, acrescido ao mínimo de 800 horas anuais prevista na Lei 9.394/96. Conforme a resolução publicada no semanário oficial de 13 a 19 deste mês, para a docência do Ensino religioso, serão aproveitados os profissionais habilitados para o Ensino fundamental nos termos da legislação do Ensino vigente, pertencentes ao quadro do Magistério Municipal. Para ressaltar a função do Professor, o Art. 11 estabelece que "Cabe ao Educador buscar constantemente as manifestações religiosas, ter clareza quanto à própria convicção de fé, consciência da complexidade da questão religiosa, facilitar o diálogo e ser interlocutor entre Escola e comunidade". Já no artigo seguinte, a resolução determina que a Secretaria de Educação e Cultura, através da Diretoria de Gestão Curricular, deverá promover cursos de capacitação para os Professores responsáveis pela docência do Ensino religioso ${ }^{4}$.

\footnotetext{
${ }^{4}$ http://www.jornaldaparaiba.com.br/noticia/100267_escolas-publicas-devem-ofertar-ensino-religioso.
} 
Desse modo, é possível perceber que o momento que vivenciamos revela um grande investimento no ensino religioso na cidade de João Pessoa, onde encontramos professores capacitados para a ministração das aulas com uma metodologia condizente com a diversidade religiosa e que faz jus ao termo "País laico".

\section{As Ciências das Religiões na Universidade Federal da Paraíba}

O curso de Ciências das Religiões na Universidade Federal da Paraíba foi e continua sendo polêmico pelo conteúdo que aborda ao ser ministrado em uma universidade federal. No entanto, o Centro de Educação aceitou o desafio de criar o departamento de Ciências das Religiões, sendoa universidade Federal da Paraíba a pioneira na preparação de profissionais qualificados dentro da academia, vindo desmistificar o que se pensava quando dizia que universidade não era lugar para estudar religiões. Desse modo, propõe um curso inovador e desafiador com uma proposta de formar academicamente professores habilitados para ensinar a disciplina de ensino religioso na sala de aula, com o objetivo de compreender o fenômeno religioso em suas dimensões e a importância da diversidade religiosa para a sociedade.

O Curso de Licenciatura em Ciências das Religiões existe desde 2009na Universidade Federal da Paraíba, enquanto a pós-graduação com o curso do Mestrado desde março de 2007, ou seja, a pós-graduação se iniciou antes da graduação. A preferência pelo nome no plural "Ciências das Religiões" se deu porque o singular "Ciência(s) da Religião" tende a pressupor a existência de um método cientifico de um objeto unitário, enquanto Ciências das Religiões pressupõe tanto o pluralismo metodológico quanto o pluralismo do objeto (MIELE, POS-

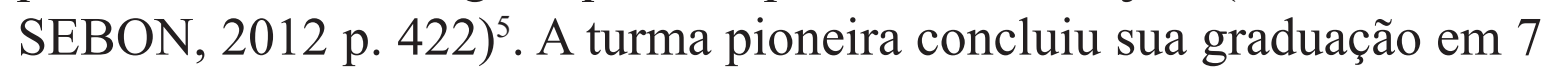
de maio de 2013.

${ }^{5}$ Numem: revista de estudos e pesquisa da religião - 09/2012. 
O Curso de Ciências das Religiões da Universidade Federal da Paraíba apresenta em sua grade curricular uma diversidade quanto aos conteúdos, como Antropologia, Filosofia, História, Psicologia, Mitologias, Cultura, Ciência, Introdução aos Sistemas Simbólicos, Estruturas Antropológicas do Imaginário, todos fazendo uma relação com as Religiões. Com essa grade curricular o curso visa odesenvolvimento de um perfil profissional para o educador proporcionando: [...] Exercitar uma efetiva visão multidisciplinar, integrar subjetividade e objetividade, ser simultaneamente agente e sujeito de sua formação ser um profissional competente e saber fazer uma reflexão crítica sobre o fenômeno religioso [...] (MIELE, 2011 pp. 41-42) .

\section{O Ensino Religioso em diálogo com as Ciências das Religiões na cidade de João Pessoa}

O objetivo do Ensino Religioso tem a proposta de verificar as diferentes culturas e o papel das tradições religiosas dentro das manifestações socioculturais:

Art. $1^{\circ} \mathrm{O}$ art. 33 da Lei $\mathrm{n}^{\circ}$ 9.394, de 20 de dezembro de 1996, passa a vigorar com a seguinte redação:

"Art. 33". O ensino religioso, de matrícula facultativa, é parte integrante da formação básica do cidadão e constitui disciplina dos horários normais das escolas públicas de ensino fundamental, assegurado o respeito à diversidade cultural religiosa do Brasil, vedadas quaisquer formas de proselitismo.

$\S 1^{\circ}$ Os sistemas de ensino regulamentarão os procedimentos para a definição dos conteúdos do ensino religioso e estabelecerão as normas para a habilitação e admissão dos professores.

$\S$ “ $2^{\circ}$ Os sistemas de ensino ouvirão entidade civil, constituída pelas diferentes denominações religiosas, para a definição dos conteúdos do ensino religioso"7.

\footnotetext{
${ }^{6}$ Curso de Graduação em Ciências das Religiões (MIELE, Neide).

${ }^{7}$ http://www.pedagogiaemfoco.pro.br/19475_97.htm.
} 
Nesse sentido, considerando a experiência vivenciada em duas escolas da rede municipal de João Pessoa ${ }^{8}$ foi possível perceber o grande avanço do Ensino Religioso nos dias atuais. As aulas são direcionadas para o ensino fundamental I e II e a maior dificuldade está na falta de material didático para os alunos. A metodologia aplicada em sala de aula, com o uso de muitos textos escritos no quadro, coloca em evidência a obrigatoriedade da disciplina, mesmo sendo optativa e não reprovativa para os alunos. O material didático utilizado na sala de aula ainda permanece sendo utilizado apenas pelos educadores, já que os alunos, em sua maioria, não recebem o livro didático, o que de certo modo justifica a queixa de alguns professores que questionam a falta de investimento no material didático. Apesar disso, estes professores desenvolvem em sua prática docente o conteúdo programático e respeitam a diversidade religiosa9.

O objetivo do curso de Ciências das Religiões, por sua vez, está centrado em:

Estudar e analisar as expressões culturais da religiosidade humana em todas as suas dimensões, formas, conteúdos, práticas e significações.

Capacitar o profissional em Ciências das Religiões para exercer a docência na disciplina Ensino Religioso na rede pública e pri$\operatorname{vada}^{10}$.

Nesse sentido, procuramos estabelecer um diálogo entre Ensino Religioso e Ciências das Religiões, trazendo propostas metodológicas que visem o melhoramento da estrutura didática em sala de aula, colocando profissionais com formação adequada para o Ensino Religioso, com amplo conhecimento na diversidade religiosa que encontramos no curso de Ciências das Religiões na Universidade Federal da Paraíba,

${ }_{8}^{8}$ Escola Municipal Darcy Ribeiro e Escola Municipal Professor Oscar de Castro.

9 Informações pessoais colhidas mediante Estágio Supervisionado feito pelas pesquisadoras Doracy Rocha Lopes e Silvania Maria da Silva.

${ }^{10}$ AS LENDAS NOS LIVROS DIDÁTICOS: uma análise mítica, artigo do GEPAI (Grupo de Estudo e Pesquisa em Antropologia do Imaginário). 
buscando constante aperfeiçoamento na área e fazendo uso de outras temáticas de ensino.

De certo modo, desconfiamos que a utilização de símbolos pode ser um aliado dos professores de Ensino Religioso, pois mostra a importância de fazer ligações simbólicas com o sagrado,até porque foi possível perceber uma base metodológica no livro $\mathrm{O}$ uso de símbolos (NASSER, 2006 ${ }^{11}$, onde é colocada em evidência a manifestação simbólica que pode ser explorada para um melhor entendimento do assunto proposto, fazendo usodo dia a dia dos alunos.Outro tema que também pode colaborar para um melhor entendimento da vivência das religiões é o rito, que traz a ressignificação dos momentos ensinados e explorados nas diferentes culturas religiosas.

Partindo do pressuposto de que a proposta de um curso de licenciatura em uma Universidade Federal tem como base a formação de professores formados em Ciências das Religiões para atuação em Ensino Religioso, com capacitação para desenvolver em sala de aula um estudo de diversidade religiosa, de respeito ao que é diferentedasua realidade, é possívelperceber a importância de se estudar a religião, não como fé ou doutrina, mas, sim, como um fenômeno que tem importância para a sociedade na qual faz parte (SENA, 2007) ${ }^{12}$.

A busca por este diálogo é benéfica e tem trazido resultados positivos, pois o melhoramento do ensino religioso e a sua qualidade é um ponto crucial para que a educação e o respeito sejam praticados.

\section{Considerações finais}

O Ensino Religioso nas escolas municipais de João Pessoa vem passando por momentos de muitos avanços, como a implantação da Capacitação de professores da rede municipal, envolvendo a formação continuada com a Especializaçãoem Ciências das Religiões, realizadas

\footnotetext{
${ }^{11}$ NASSER, Maria Celina Cabrera. O uso dos símbolos: sugestões para sala de aula.

${ }^{12}$ SENA, Luzia. Ensino Religioso e formação docente: Ciências da Religião e Ensino Religioso em diálogo.
} 
em parceria com SEDEC-JP, o CE-Universidade Federal da Paraíba e Editora Paulinas, com vistas ao melhoramento do Ensino Religioso na sala de aula,o que, de certo modo,demonstra a busca por um ensino de qualidade na área do Ensino Religioso.

Apesar do avanço encontrado no Ensino Religiosonas escolas municipais em João Pessoa, ainda há muito por fazer, pois temos muitos professores com formação em outras áreas (história, geografia, artes, português) ministrando o Ensino Religioso. Desejamos que com a graduação da $1^{\mathrm{a}}$ turma de Licenciatura em Ciências das Religiões essa realidade mude e estes profissionais que possuem a capacitação necessária para ministrar aulas do Ensino Religioso ocupem espaço no mercado de trabalho.

O Curso de Ciências das Religiões na Universidade Federal da Paraíba tem como propostaa formação de professores capacitados para ministrar Ensino Religioso. Ele objetiva também a compreensão do fenômeno religioso em suas dimensões e a explanação da diversidade religiosa presente na sociedade, trazendo uma nova perspectiva em relação ao processo educação-religião e respeitando as diferentes culturas religiosas. Nesse sentido, ele vem apresentando o seu valor, desde a graduação da $1^{\mathrm{a}}$ turma licenciada, a proposta de 20 vagas de estágio remunerado feita pela SEDEC-JP no mês de maio de 2013, em uma aula inaugural feita pelo CE-UFPB. As mudanças ocorrem paulatinamente e continuamos na busca de um Ensino Religioso de qualidade e livre de proselitismo.

O diálogo entre o Ensino Religioso e as Ciências das Religiões vem alcançando avanços memoráveis com um novo olhar para o Ensino Religioso, utilizando-se práticas vivenciadas no CR-UFPB da diversidade, da pluralidade e da extinção do proselitismo, com a busca incessante de profissionais capacitados e preparados para um assunto tão extenso e que se encontra em constante transformação. A religião é viva e sofre mudanças em sua trajetória. Assim, foi e continua sendo possível perceber que "a ignorância é a mãe da intolerância". Nesse sentido, se dá a busca para o conhecimento. 


\section{Referências}

HOLMES, Maria José Torres. Ensino Religioso: Problemas e desafios. João Pessoa: Dissertação de Mestrado UFPB. Mestrado em Ciências das Religiões, 2010.

MIELE, Neide. Curso de Graduação de Ciências das Religiões. João Pessoa: Editora UFPB, 2011.

MIELE, Neide; Possebon, Fabrício. Ciências das Religiões: Proposta pluralista na UFPB. Numem revista de estudos e pesquisa da religião - Juiz de Fora, 2009.

NASSER, Maria Celina Cabrera. O uso de símbolos: Sugestões para sala de aula. São Paulo: Editora Paulinas, 2006.

SENA, Luiza. Ensino religioso e formação docente: Ciência da religião e ensino religioso em diálogo. $2^{\text {a }}$ Ed., São Paulo: Editora Paulinas, 2007.

Extraído do site http://www.jornaldaparaiba.com.br/noticia/100267 escolas-publicas-devem-ofertar-ensino-religioso, no dia 14 de maio de 2013.

Extraído do site http://www.joaopessoa.pb.gov.br/secretarias/sedec, no dia 14 de maio de 2013.

Extraído do site http://www.pedagogiaemfoco.pro.br/19475_97.htm, no dia 14 de maio de 2013. 